\title{
Forecasting Peak-Day Consumption for Year-Ahead Management of Natural Gas Networks
}

\author{
Ronan Oliver \\ Technological University Dublin, ronan.oliver@tudublin.ie \\ Aidan Duffy \\ Technological University Dublin, aidan.duffy@tudublin.ie \\ Bernard Enright \\ Technological University Dublin, bernard.enright@tudublin.ie
}

See next page for additional authors

Follow this and additional works at: https://arrow.tudublin.ie/engschcivart

Part of the Engineering Commons

\section{Recommended Citation \\ This Article is brought to you for free and open access by the School of Civil and Structural Engineering at ARROW@TU Dublin. It has been accepted for inclusion in Articles by an authorized administrator of ARROW@TU Dublin. For more information, please contact arrow.admin@tudublin.ie, aisling.coyne@tudublin.ie, gerard.connolly@tudublin.ie.}

Duffy, A. (2016). Forecasting peak-day consumption for year-ahead management of natural gas networks. Utilities Policy, vol. 44, Feb.,pp. 1-11. doi.org/10.1016/j.jup.2016.10.006

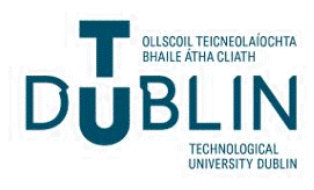




\section{Authors}

Ronan Oliver, Aidan Duffy, Bernard Enright, and Rodger O'Connor

This article is available at ARROW@TU Dublin: https://arrow.tudublin.ie/engschcivart/76 


\title{
Forecasting peak-day consumption for year-ahead management of natural gas networks
}

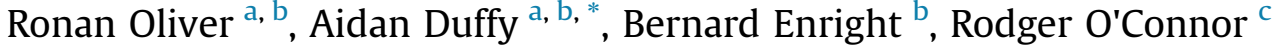 \\ a Dublin Energy Lab, Dublin Institute of Technology, Ireland \\ ${ }^{\mathrm{b}}$ School of Civil and Structural Engineering, Dublin Institute of Technology, Ireland

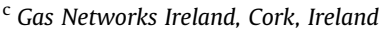

\section{A R T I C L E I N F O}

\section{Article history:}

Received 5 February 2015

Received in revised form 24 October 2016

Accepted 24 October 2016

Available online 29 November 2016

\section{Keywords:}

Gas networks

Security of supply

Degree day

\begin{abstract}
A B S T R A C T
Security of supply is at the forefront of energy policy in the EU and elsewhere. This paper develops a methodology to forecast peak-day gas consumption for the consideration of gas transmission system operators. It is developed for the domestic and small-to-medium enterprise (SME) gas market, based on a review of current practice. From this assessment, a climate-adjusted network degree day $\left(N D D_{\mathrm{CA}}\right)$ variable is developed to estimate the weather-dependent gas consumption of such markets. We show that solar radiation significantly affects gas consumption and should be considered in consumption models. The study also quantifies the difference in capacity required under alternative gas supply standards.
\end{abstract}

(C) 2016 Elsevier Ltd. All rights reserved.

\section{Introduction}

For many countries, the natural gas network forms a key component of their energy supply infrastructure, delivering gas to power stations, industry, small-to-medium enterprises (SMEs), and domestic dwellings. The management and delivery of this infrastructure is provided by transmission system operators (TSOs, or network operators) that must ensure the safety and security of gas supply to the consumer.

To provide this service, TSOs must make network planning decisions to safeguard against diminished supply capacity under extreme cold weather conditions. Of primary concern in this process is the requirement to maintain supplies to domestic consumers and essential social service providers, including childcare, healthcare and educational facilities whose occupants may be at risk during these events. Indeed, European Union (EU) member states are required to prioritize gas supply for these consumers (and for a limited proportion of SMEs) during periods of extreme weather (Official Journal of the European Union, 2010).

In advance of each winter, TSOs develop peak-consumption estimates for their population of domestic and SME consumers.

\footnotetext{
* Corresponding author. School of Civil and Structural Engineering, DIT, Bolton Street, Dublin 1, Ireland.

E-mail address: aidan.duffy@dit.ie (A. Duffy).
}

These estimates are used by TSOs to assess the adequacy of their network for possible future extreme cold weather periods in order to inform year-ahead network operations and to fulfil regulatory requirements such as 'winter outlook' reports to the energy regulator, energy suppliers, and other stakeholders. In addition, the estimates can be used by the TSO to determine network capacity bookings and charges to energy suppliers, for planning the gas network infrastructure used to supply their customers and to calculate network maintenance and development costs for approval by the regulator. This is particularly relevant since significant investments in gas network infrastructure are planned in order to increase security of gas supplies to Europe (Insight_E, 2014). It is therefore important that the TSO follows an accurate and transparent peak gas consumption estimation methodology.

In general, TSOs calculate peak gas consumption to meet specified supply standards using a gas consumption model. Such standards define the extreme weather event during which the gas supply must be maintained. However, different definitions of extreme weather are used in the EU's supply standard (Official Journal of the European Union, 2010) and in European TSO supply standards (Czech Energy Regulatory Office, 2011; Energinet, 2011; FPS Economy, 2014; Gas Networks Ireland, 2007; Gas Transport Services BV, 2011; GRTgaz, 2013; National Grid, 2012) with respect to:

1. the weather variable used to estimate peak-gas consumption; 
2. the return level of the weather variable used to quantify extreme weather (typically a 1 -in-20 or 1 -in-50 year return event); and

3. the duration of the extreme weather event to be managed by the TSO.

With regard to weather variables, some supply standards specify temperature while others apply a 'composite weather variable' (CWV) that accounts for additional effects (such as wind speed) on gas consumption (see Table 1). None consider solar radiation, which recent research suggests may be an important factor in heating demand in domestic buildings (Soldo et al., 2014). For example, solar heat gains in buildings can have a significant impact on internal temperatures and, consequently, on the need for space heating and gas consumption.

This study assesses the impacts of differences in supply standards and new forecasting models on peak network demand forecasting. The specific objectives of the study are:

1. to review the supply standards and the modelling methods used by European TSOs to estimate peak gas consumption;

2. to develop a new CWV to model gas consumption, which accounts for a more weather effects than currently used, including solar radiation;

3. to apply the new approach to model gas consumption in a European country and quantify the resulting improvement in accuracy compared to existing approaches; and
4. to investigate the relative difference in the peak gas consumption required by alternative supply standards for this country, based on the new CWV.

Any resulting improvement in modelling accuracy can help TSOs reduce the error of peak gas consumption estimates, thus allowing them to develop more efficient network development plans. This would help in avoiding either under- or over-investment in the gas network. In the former case, security of supply is enhanced. In the latter case, excessive investment in infrastructure such as pipelines, compressors, and/or gas storage facilities is avoided and energy costs to the consumer are minimised.

\section{Current practice}

In this section, the methods applied by European TSOs to quantify peak gas consumption are investigated. A review of a sample of supply standards is presented, followed by a description of current peak gas consumption modelling methods.

\subsection{Supply standards}

In Table 1, the EU's supply standard and a sample of European TSOs supply standards are summarised with respect to the criteria used to describe a peak consumption event, the weather variable used to quantify this event, and additional information in relation to the methodology used to create the relevant weather variable's

Table 1

European peak natural gas supply standards.

\begin{tabular}{|c|c|c|}
\hline Region & Consumption Criteria & Notes \\
\hline $\begin{array}{l}\text { European Union } \\
\text { (Official Journal of the European Union, } \\
\text { 2010) }\end{array}$ & $\begin{array}{l}\text { Extreme temperatures during a } 7 \text { day peak period } \\
\text { occurring with a } 1 \text {-in- } 20 \text { year probability. }\end{array}$ & $\begin{array}{l}\text { These extreme temperatures have been quantified for the Belgian } \\
\text { market as a 7-day average temperature that is equivalent to the 1-in-20 } \\
\text { year 7-day heating degree day total (FPS Economy, 2014). }\end{array}$ \\
\hline $\begin{array}{l}\text { Belgium } \\
\text { (FPS Economy, 2014) }\end{array}$ & 5 consecutive days between -10 and $-11^{\circ} \mathrm{C}$. & - \\
\hline $\begin{array}{l}\text { Czech Republic } \\
\text { (Czech Energy Regulatory Office, 2011) }\end{array}$ & $\begin{array}{l}5 \text { consecutive days when the average daily } \\
\text { temperature does not rise above }-14{ }^{\circ} \mathrm{C}\end{array}$ & - \\
\hline $\begin{array}{l}\text { Denmark } \\
\text { (Energinet, 2011) }\end{array}$ & $\begin{array}{l}3 \text { consecutive days with a daily average } \\
\text { temperature of down to }-13^{\circ} \mathrm{C} \text { i.e. the } 1 \text {-in-20 year } \\
\text { event }\end{array}$ & - \\
\hline $\begin{array}{l}\text { France } \\
\text { (GRTgaz, 2013) }\end{array}$ & $\begin{array}{l}\text { Very low temperatures over } 3 \text { consecutive days } \\
\text { with a 1-in-50 year probability }\end{array}$ & $\begin{array}{l}\text { These very low temperatures have been quantified by an effective daily } \\
\text { temperature as follows (GRTgaz, 2009): } \\
T_{\mathrm{EFF}, \mathrm{D}}=0.64 T_{\mathrm{AVG}, \mathrm{D}}+0.24 T_{\mathrm{AVG}, \mathrm{D}-1}+0.12 T_{\mathrm{AVG}, \mathrm{D}-2} \\
\text { where: } T_{\mathrm{EFF}, \mathrm{D}} \text { is the effective temperature for a given day (D); and } T_{\mathrm{AVG}, \mathrm{D}} \text {, } \\
T_{\mathrm{AVG}, \mathrm{D}-1} \text { and } T_{\mathrm{AVG}, \mathrm{D}-2} \text { are the average temperatures for day (D), and the } \\
\text { preceding days (D-1 and D- } 2 \text { ), respectively. } \\
\text { This effective daily temperature accounts for the network's } \\
\text { consumption response lag to the current and preceding days' } \\
\text { temperature. } \\
\text { A 1-in-50 year estimate of this effective temperature is provided by } \\
\text { Météo France, which also accounts for climate change, using } 30 \text { years of } \\
\text { temperature data (GRTgaz, 2009). }\end{array}$ \\
\hline $\begin{array}{l}\text { Ireland } \\
\text { (Gas Networks Ireland, 2007) }\end{array}$ & $\begin{array}{l}\text { Peak daily consumption is estimated for a weekday } \\
\text { by the } 1 \text {-in- } 50 \text { year value of a CWV. }\end{array}$ & $\begin{array}{l}\text { This CWV accounts for the network's consumption response lag, } \\
\text { temperature, seasonal consumption, wind chill and exceptionally cold } \\
\text { temperatures; in addition to heating degree day transformations to } \\
\text { linearity. } \\
\text { The } 1 \text {-in- } 50 \text { year value of this CWV is estimated using a generalised } \\
\text { extreme value model. }\end{array}$ \\
\hline $\begin{array}{l}\text { The Netherlands } \\
\text { (Gas Transport Services BV, 2011) }\end{array}$ & $\begin{array}{l}\text { Average daily temperature of }-17^{\circ} \mathrm{C} \text { i.e. the } 1 \text {-in- } 50 \\
\text { year event }\end{array}$ & - \\
\hline $\begin{array}{l}\text { The United Kingdom } \\
\text { (National Grid, 2012) }\end{array}$ & $\begin{array}{l}\text { Peak consumption is forecast as the mean of } \\
\text { multiple 1-in- } 20 \text { year return levels estimated from } \\
\text { simulated long-term gas consumption series } \\
\text { generated using a CWV. }\end{array}$ & $\begin{array}{l}\text { This CWV accounts for the network's consumption response lag (using } \\
\text { the following effective temperature), seasonal consumption and wind } \\
\text { chill; and utilises a four case transformation to linearity. } \\
\text { The effective daily temperature in this CWV is calculated using an } \\
\text { exponential filter function as follows: } \\
T_{\mathrm{EFF,D}}=0.5 T_{\mathrm{AVG}, \mathrm{D}}+0.5 T_{\mathrm{EFF}, \mathrm{D}-1} \\
\text { where: } T_{\mathrm{EFF}, \mathrm{D}} \text { is the effective temperature for a given (gas) day (D); } \\
T_{\mathrm{AVG}, \mathrm{D}} \text { is the (weighted) average temperature for the day; and } T_{\mathrm{EFF}, \mathrm{D}-1} \text { is } \\
\text { the effective temperature for the previous day (D-1) }\end{array}$ \\
\hline
\end{tabular}


return level and peak gas consumption. The EU standard was developed following the Russian-Ukrainian gas crisis in 2009 (Insight_E, 2014), when Central and Eastern European countries experienced significant gas shortages (European Commission, 2011). In the table, the peak gas consumption criterion of the standard is provided; two additional criteria in relation to storage capacity requirements complete the standard but are not reported here. The peak gas requirement in the EU standard is the minimum short-term quantity of gas that member state TSOs must make available to 'protected' (mainly domestic) consumers.

As seen in Table 1, some countries use a longer return period than the EU requirement but for shorter consumption periods. It is understood that this is the case in France (GRTgaz, 2013), the Netherlands (Gas Transport Services BV, 2011), and Ireland. In Ireland, the relatively high 50-year return period is used due to the country's limited storage and poor interconnectivity with other gas networks.

\subsubsection{Weather variables}

Table 1 shows that temperature is the most common weather variable used to estimate peak gas consumption. However, more complex estimators of gas consumption have also been developed by European TSOs. In France, for example, an effective temperature is applied that is calculated using a weighted temperature filter to account for the lag in response of daily network gas consumption to changes in weather; this method uses the current and two preceding days' temperatures. In the UK, a CWV is applied that accounts for effective temperature, seasonal consumption, and wind chill. This effective temperature is calculated using an exponential filter function. The CWV also includes a four-case transformation function to account for effects such as transitional periods in the spring and autumn when consumers stop and start using their building's heating system (National Grid, 2012). In Ireland, a different CWV is applied that accounts for similar gas consumption effects using heating degree days (HDDs) (for example, see Eq. (A.1)).

Although an exact description of the estimation methods used in these CWVs is not readily available, each accounts for multiple weather effects on gas consumption using a single variable. They include outdoor temperature, wind chill, the thermal inertia of the network's building stock and the seasonal consumption behaviour of the consumer population. These and additional gas consumption effects are described in Table 2. In this study, we investigate whether it is possible to improve gas modelling accuracy by developing a new CWV. This can be achieved mainly by accounting for the additional effect of solar radiation, which is not considered in European peak supply standards (as seen in Table 2). The reasons for omitting solar radiation are unclear. One possibility is that, compared to temperature and wind speed, solar data are relatively new. For example, in Ireland, solar data have been available since 1976 (see Section 3.1.2) whereas both temperature and wind speed data have been available since the 1940s. Thus, TSOs may have not yet responded to solar data availability in forecasting peak-day gas consumption. A second reason may be that, because gas network models are already quite accurate, there is no strong incentive to improve existing approaches. For example, a coefficient of determination $\left(R^{2}\right)$ value of 0.8452 is reported in Table 5 for a gas network model that simplistically uses HDDs. The relatively recent availability of solar data now allows solar effects to be included in peak-day forecasting models. Appendix A provides details of how

Table 2

Gas consumption effects applied in European peak supply standards.

\begin{tabular}{|c|c|c|}
\hline Effect & Description & Applied by: \\
\hline Outdoor temperature & $\begin{array}{l}\text { Relates to the indoor-outdoor temperature differential that drives both } \\
\text { fabric and air-infiltration heat loss from buildings. Lower outdoor } \\
\text { temperatures result in higher gas consumption. }\end{array}$ & $\begin{array}{l}\text { - EU supply standard (Official Journal of the European Union, 2010). } \\
\text { - Belgium (FPS Economy, 2014). } \\
\text { - Czech Republic (Czech Energy Regulatory Office, 2011). } \\
\text { - Denmark (Energinet, 2011). } \\
\text { - France (GRTgaz, 2009). } \\
\text { - Ireland (Gas Networks Ireland, 2007). } \\
\text { - The Netherlands (Gas Transport Services BV, 2011). } \\
\text { - The United Kingdom (National Grid, 2012). }\end{array}$ \\
\hline Wind chill & $\begin{array}{l}\text { Relates to building air-infiltration heat loss, and can be given by the } \\
\text { product of wind speed and the indoor-outdoor temperature differential } \\
\text { estimated by heating degree days (see Eq. (A.2f) in Appendix A). } \\
\text { Increased wind-chill results in higher gas consumption. }\end{array}$ & $\begin{array}{l}\text { - Ireland (Gas Networks Ireland, 2007). } \\
\text { - The United Kingdom (National Grid, 2012), for wind speeds above a } \\
\text { threshold. }\end{array}$ \\
\hline Solar radiation & $\begin{array}{l}\text { Relates to solar heat gain in buildings and affects indoor temperature - } \\
\text { and therefore building fabric and air-infiltration heat loss (wind chill). } \\
\text { Lower solar radiation results in higher gas consumption. }\end{array}$ & $\begin{array}{l}\text { - Solar radiation is not modelled by the alternative European peak } \\
\text { supply standards. }\end{array}$ \\
\hline Thermal memory & $\begin{array}{l}\text { Describes the prolonged effect that recent days' outdoor temperatures } \\
\text { have on daily building heat consumption due to the intermittent } \\
\text { operation of heating systems and the thermal mass of buildings. The } \\
\text { effective temperature on a given day is dependent on outdoor } \\
\text { temperature for several days previously. }\end{array}$ & $\begin{array}{l}\text { - France, using an effective temperature that is calculated using a } \\
\text { weighted temperature filter (GRTgaz, 2009). } \\
\text { - Ireland, using a weighted heating degree day filter (Gas Networks } \\
\text { Ireland, 2007). } \\
\text { - The United Kingdom, using an effective temperature that is calculated } \\
\text { using an exponential filter function (National Grid, 2012). }\end{array}$ \\
\hline $\begin{array}{l}\text { Variable base } \\
\text { temperatures }\end{array}$ & $\begin{array}{l}\text { This is a network level effect that relates to the variation of building base } \\
\text { temperatures over the consumer population; where base temperature } \\
\text { describes the outdoor temperature at which building fabric and air- } \\
\text { infiltration heat loss is balanced by incidental heat gains from electrical } \\
\text { appliances, people etc. without any additional heat from the building's } \\
\text { heating system. Higher base temperatures result in higher gas } \\
\text { consumption. }\end{array}$ & $\begin{array}{l}\text { - The United Kingdom, as part of a four case transformation function } \\
\text { (National Grid, 2012). }\end{array}$ \\
\hline Seasonal consumption & $\begin{array}{l}\text { This is an effect observable at a network level that relates to the } \\
\text { response of consumers' to unseasonable weather conditions whereby } \\
\text { seasonal or normal gas consumption levels are maintained for that time } \\
\text { of year e.g. the effect of inefficient consumers who do not reduce their } \\
\text { heating needs during mild temperature periods in the wintertime. }\end{array}$ & $\begin{array}{l}\text { - Ireland, using a seasonal heating degree day series (Gas Networks } \\
\text { Ireland, 2007). } \\
\text { - The United Kingdom, using a 'pseudo' seasonal effective temperature } \\
\text { calculated by averaging and smoothing the effective temperature over } \\
\text { a number of years and adjusting this to better reflect seasonal gas } \\
\text { consumption (National Grid, 2012). }\end{array}$ \\
\hline
\end{tabular}


we developed a new CWV to account for the effect of solar radiation.

\subsubsection{Peak consumption criteria}

TSO supply standards use a variety of alternative definitions to quantify short-term peak consumption. Apart from the UK, where simulated gas consumption series are applied, a peak consumption event is described by a weather variable of some form, quantified by a return level for a single day or for several days.

The method chosen for estimating return levels depends on the specified weather variable and the length of the available climate data; long-term climate data can allow simple empirical estimation, while shorter datasets may require extreme-value statistical methods. In this regard, the use of temperature to estimate consumption has the advantage that long-term temperature datasets are readily available from local meteorological stations. However, in Ireland records including both temperature and wind-speed are available only since the 1940s. The current Irish CWV therefore uses a 1-in-50 year return level, extrapolated using a generalised extreme value (GEV) model. A similar approach is used in this study in the development of an improved CWV. We show that this approach gives significantly better results than simpler models based on temperature alone. The shorter historical record of the weather data used in the model requires the use of an extreme value model that can be justified statistically using an AndersonDarling goodness-of-fit test (Ahmad, 1989).

\subsubsection{Modelling techniques}

In the gas industry, alternative methods can be found to model gas consumption for general forecasting and gas management purposes, including: regression models (Gas Networks Ireland, 2007); auto-regressive integrated moving-average or autoregressive models including exogenous variables (Aras and Aras, 2004; Brabec et al., 2008); neural networks (Brown et al., 1994; Kizilaslan and Karlik, 2008; Peharda et al., 2001; Khotanzad et al., 2000); and generalised additive models (Brabec et al., 2010). In relation to peak consumption estimation, regression-based models are considered to offer a more transparent methodology compared to the alternatives. This is an important consideration when there are stakeholders such as energy regulators and energy suppliers who are concerned with methodological transparency. It is understood that regression-based methods are used for the estimation of peak consumption for the French (GRTgaz, 2009), Irish (Gas Networks Ireland, 2007) and UK (National Grid, 2012) gas markets.

For the Irish gas market, peak gas consumption is forecast for a weekday using a 1-in-50 year CWV return level estimated by a GEV distribution, fitted using probability weighted moments (Hosking et al., 1985). The forecast model is a regression model of recent years' daily gas consumption, estimated by a CWV and dummy variables for weekends, public holidays, holiday periods and the heating season (Gas Networks Ireland, 2007). For the UK gas market, peak gas consumption is forecast as the mean of multiple 1-in20 year return levels estimated by Gumbel-Jenkinson extreme value models of simulated long-term gas consumption series. These simulated gas consumption series are created using a model of daily gas consumption employing historical CWV values and random error terms (National Grid, 2012).

\section{Methodology}

In this section we describe the data sources used in the study, followed by a description of a new CWV, the 'climate-adjusted network degree day' $\left(N D D_{\mathrm{CA}}\right)$. The gas consumption model based on this new estimator is explained. We then describe how it is used to estimate peak-day gas consumption, based on $N D D_{\mathrm{CA}}$ return levels that are quantified by an extreme value model.

\subsection{Data}

This study is based on recent daily gas consumption data for the Irish non-daily metered (NDM) gas market and long-term climate data from Dublin Airport. These data were provided by Gas Networks Ireland (the network operator) and the Irish Meteorological Office respectively.

\subsubsection{NDM market consumption data}

The Irish NDM market is comprised consumers with gas demands that justify four to twelve manual meter readings per year; this compares to large consumers that may be metered on a daily basis.

In this study, weather data and daily consumption data for the Irish NDM gas market for three gas years (October 2009 to September 2012) are used to estimate $N D D_{\text {CA. The Irish NDM gas }}$ market includes more than 650,000 consumers, predominantly domestic dwellings and some SMEs, accounting for the majority of connections to Ireland's gas distribution networks and accounting for approximately $66 \%$ and $33 \%$ of NDM annual consumption, respectively.

These data present an opportunity to validate peak consumption estimation methods using daily consumption figures from January and December 2010, when extremely cold winter periods were observed in Ireland. The gas consumption data for these extremely cold days can be used to quantify the accuracy of $N D D_{\mathrm{CA}}$ when used to model peak gas consumption.

\subsubsection{Climate data}

Daily climate data from Dublin Airport are used to estimate $N D D_{\text {CA }}$. This dataset consists of daily temperature, wind-speed, and global radiation values. The length of this data series is limited by global radiation, which became available in 1976. Occasional missing global radiation values in the dataset were replaced by 30 year average values. These missing values account for less than $1 \%$ of the observations in the global radiation data.

\subsection{Climate-adjusted network degree days}

$N D D_{\mathrm{CA}}$ s are similar to a heating degree days (HDDs) in that they are based on temperature differences between the heated building stock and external environment. However, they also include the temperature effects of wind, sunshine, thermal inertia of buildings, and seasonal effects on network gas consumption, all of which are described below.

As described in detail in Appendix A, the derivation of $N D D_{\mathrm{CA}} \mathrm{S}$ is presented as a series of additions and adjustments to the HDD variable, with each step resulting in a gas consumption estimator with greater accuracy than the last. These incrementally improved estimators are similar to the range of weather variables used by European TSOs. The derivation begins with a description of HDDs and how they account for the effect of outdoor temperatures using a base temperature $\left(T_{\mathrm{B}}\right)$ parameter. Next, weather-adjusted $H D D$ $\left(H D D_{\mathrm{WA}}\right)$ is derived that accounts for the additional effects of solar heat gain, wind chill, and building fabric thermal 'memory', by adjusting $H D D$ using solar radiation $\left(\gamma_{1}\right)$, wind speed $\left(\gamma_{2}\right)$, and building fabric thermal 'memory' or effective temperature $\left(\alpha_{1}\right)$ parameters. The term $N D D_{\mathrm{CA}}$ is then developed to account for the additional effects of variable building base indoor temperatures and seasonal consumption, by adjusting $H D D_{\mathrm{WA}}$ using upper and lower base temperatures $\left(T_{\mathrm{B}, \mathrm{upr}}\right.$ and $\left.T_{\mathrm{B}, \mathrm{lwr}}\right)$ and a seasonality $\left(\omega_{1}\right)$ parameter.

Table 2 describes the effects estimated by $N D D_{\mathrm{CA}}$ and 
summarises where these effects have already been accounted for in the various European supply standards. We see that the United Kingdom's supply standard applies the closest alternative weather variable, but does not account for solar radiation. Although the effect of solar radiation is not included in existing variables, it is included in $N D D_{\mathrm{CA}}$ as it has recently been shown to have an important effect on network and individual dwelling gas consumption (Soldo et al., 2014) and because simpler sunshine variables have previously been used to model network gas consumption in the United States (Brown et al., 1994) and Australia (ACIL Tasman, 2012).

Solar radiation is used in this analysis instead of sunshine hours since it provides better estimates of the indoor-outdoor temperature differential that drives space heating and gas consumption. Importantly, it is not significantly correlated with Irish outdoor temperatures and can therefore be used as an additional variable in statistical modelling. Moreover, numerical weather prediction models are now available to provide better forecasts of this variable, in particular to support the deployment of solar-PV (MET Eireann, 2014; Nielsen et al., 2014). It can therefore be used for forecasting purposes. Although daily solar radiation forecast errors are not available locally, hourly solar radiation forecast errors between 26.2 and $40.5 \%$ have been reported in Germany using alternative numerical weather prediction (NWP) models (Lorenz et al., 2009). Using hourly solar radiation data for Dublin Airport, it has been found that the largest of these hourly errors $(40.5 \%)$ represents a daily solar radiation forecast error of $13.2 \%$. This error and daily forecast errors published for temperature and windspeed in the UK (Met Office, 2015) are applied in validation tests of $N D D_{\mathrm{CA}}$ in Section 4.1 .

\subsection{Gas consumption model}

The parameters of the $N D D_{\mathrm{CA}}$ estimator are determined within the following gas consumption model using the non-linear least squares (NLS) method.

$C_{\mathrm{WD}}=b_{0}+b_{1} N D D_{\mathrm{CA}}+\sum_{y=1}^{2}\left(\Delta b_{0, \mathrm{y}} D V_{\mathrm{y}}+\Delta b_{1, y} D V_{y} N D D_{\mathrm{CA}}\right)+\varepsilon_{W D}$

where: $C_{\mathrm{WD}}=$ domestic and SME gas market consumption for a given weekday (WD);

WD = weekdays, excluding public holidays and the Christmas period: 24th December to the day before the first working day in the New Year:

$b_{0}=$ model intercept for the most recent gas-year: Oct'11Sept'12, and an estimate of the average weekday weatherindependent market gas consumption in this gas-year;

$b_{1}=N D D_{\mathrm{CA}}$ coefficient for the most recent gas-year: Oct'11Sept'12, the product of which is an estimate of weatherdependent market gas consumption for a given weekday in this gas-year;

$N D D_{\mathrm{CA}}=$ climate-adjusted network degree day (for a given weekday), which includes: 1 ) the non-linear parameters: $T_{\mathrm{B}, \mathrm{upr}}$, $T_{\mathrm{B}, \mathrm{lwr}}, \omega_{1}, \alpha_{1}, \gamma_{1} \& \gamma_{2}$ to estimate the effect of variable base temperatures $\left(T_{\mathrm{B}, \mathrm{upr}} \& T_{\mathrm{B}, \mathrm{Iwr}}\right)$, seasonal consumption $\left(\omega_{1}\right)$, building fabric thermal 'memory' or effective outdoor temperature $\left(\alpha_{1}\right)$, solar radiation $\left(\gamma_{1}\right)$ and wind chill $\left(\gamma_{2}\right)$; and 2$)$ the manually specified parameters: $m$ and $n$ that represent the moving average window width $(m)$ and the number of years $(n)$ used to calculate seasonal degree day values in order to estimate seasonal consumption behaviour; here they are given by 13 days and 30 years, respectively, although these can be profiled separately if required (see Table 2 and Appendix A);

$y=$ previous gas-years, $1=$ Oct'10-Sept'11 and $2=$ Oct'09 to Sept'10;

$\Delta b_{0} \mathrm{~s}=$ differential intercepts required for the previous gasyears $(y)$;

$D V \mathrm{~s}=$ dummy variables to indicate the previous gas-years $(y)$, which have a value of 1 if a data point is in the designated year, otherwise the value is zero, thus allowing different linear models to apply to each of the three gas-years examined;

$\Delta b_{1} \mathrm{~s}=$ differential $N D D_{\mathrm{CA}}$ coefficients required for the previous gas-years $(y)$; and

$\varepsilon \mathrm{WD}=$ residual (model error) for a given weekday (WD).

Weekday consumption is used to estimate the parameters of the $N D D_{\text {CA }}$ estimator because consumption for the Irish domestic and SME gas market is greater on weekdays than at weekends, on public holidays and during the Christmas period when there is less SME activity. These alternative day-types are excluded in the modelling process as they would each require additional differential intercepts and slopes, thus adding unnecessary complication to the model.

The model is estimated using consumption data starting in the 2009-2010 gas year (October-September) in order to include the extremely cold winter periods experienced in Ireland in January and December 2010 in the evaluation of the modelling accuracy given by $N D D_{\mathrm{CA}}$ in Fig. 1 . However, as the consumption data span three years a number of potential influences may apply, such as: increased consumer numbers; improved building fabric standards; or housing energy efficiency programs. Over time, such effects can impact on the estimated intercept and slope of a linear gas consumption model. This is accounted for in our model using differential intercepts and slopes for each of the preceding gas years. To help convergence to a global NLS solution, starting values are stipulated for each parameter as shown in Table 3.

The linear parameters $b_{0}$ and $b_{1}$ estimated for the most recent gas year are then used to estimate peak daily gas consumption for the subsequent heating season, as follows:

$\widehat{C}_{\text {Oct'12-Sept'13 }}=b_{0}+b_{1} N D D_{\mathrm{CA}}$

where $\hat{C}_{\text {Oct'12-Sept'13 is the peak-day gas consumption forecast for }}$ the next gas-year (2012-2013) using $N D D_{\text {CA }}$ return levels quantified by separate generalised extreme value or $\operatorname{GEV}\left(x_{i} ; \mu, \sigma, k\right)$ models (Hosking et al., 1985); the location $(\mu)$, scale $(\sigma)$, and shape $(k)$ parameters of which are estimated using probability weighted moments (Ahmad, 1989) and block maxima $\left(x_{i}\right)$ (i.e. maximum $N D D_{\mathrm{CA}}$ values) for each gas year of the available climate data.

\section{Results and discussion}

The results of our analysis begin with the implementation of the weekday gas consumption model, including the estimation of the parameters of the $N D D_{\text {CA. }}$. The accuracy of this model is assessed and results are then presented for the estimation of peak-day gas consumption in Ireland based on alternative supply standards.

\subsection{Gas consumption model}

In this section the gas consumption model (Eq. (1)) and $N D D_{\mathrm{CA}}$ (Eq. (A.3) in Appendix A) are described in terms of: 1) the parameter estimates; 2) the in-sample model accuracy; and 3) a comparative analysis of the parameters of the $N D D_{\mathrm{CA}}$ estimator with respect to model accuracy.

The parameter estimates for the gas consumption model and 

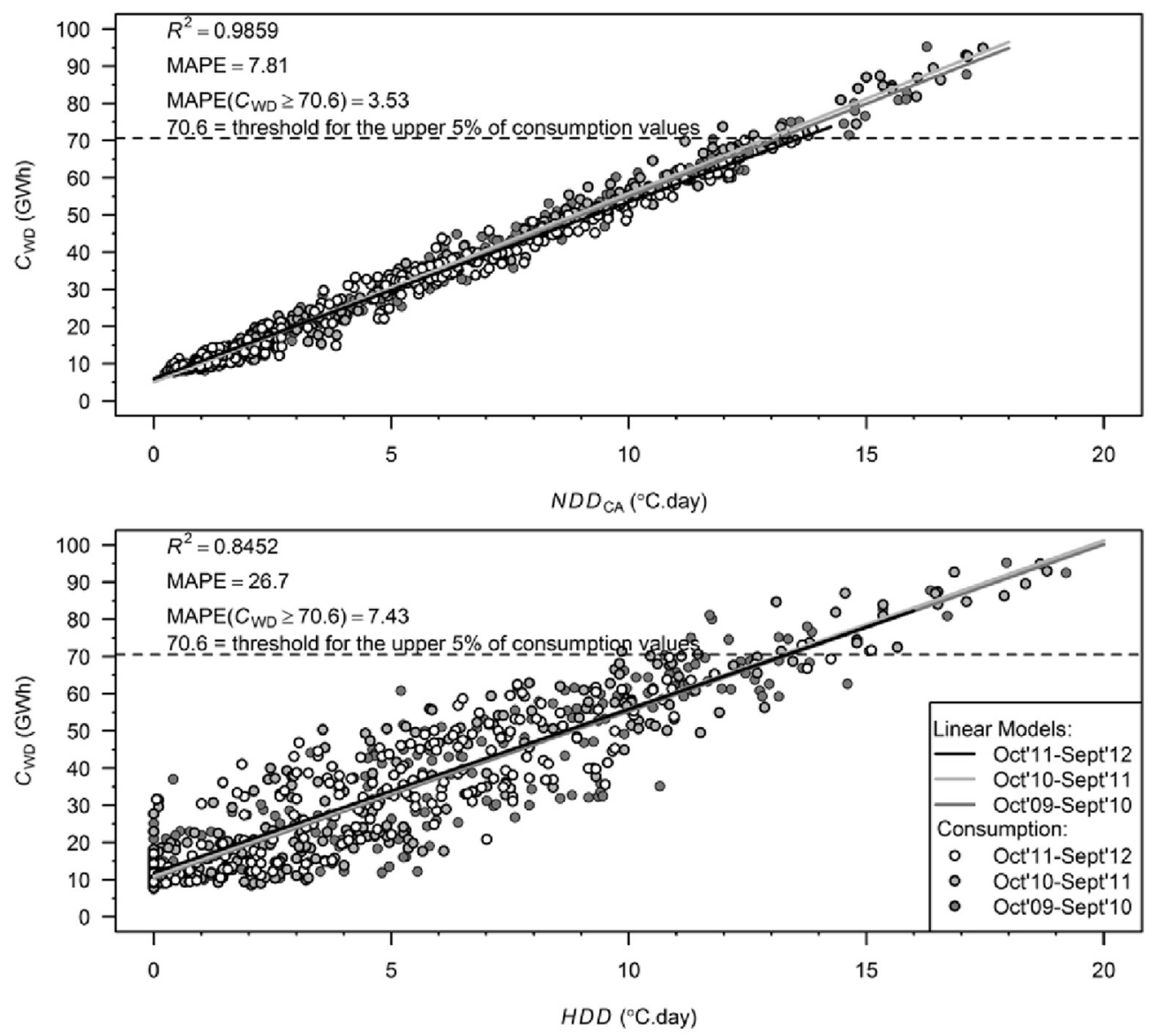

Fig. 1. Linear relationship between gas consumption for both $N D D_{\mathrm{CA}} \mathrm{S}$ and $H D D s$.

Table 3

Model parameter starting values.

\begin{tabular}{|c|c|}
\hline Parameter & Starting Value \\
\hline$b_{0}$ & 5 \\
\hline$b_{1}$ & 5 \\
\hline$\Delta b_{0, \text { Oct'10-Sept'11 }}, \Delta b_{0}$,Oct'09-Sept'10, $\Delta b_{1}$,Oct'10-Sept'11, and $\Delta b_{1}$,Oct'09-Sept'10, & 0 \\
\hline$T_{\mathrm{B}, \mathrm{upr}}$ & 20 \\
\hline$T_{\mathrm{B}, \mathrm{lwr}}$ & 15 \\
\hline$\omega_{1}, \gamma_{1}, \gamma_{2}$ and $\alpha_{1}$ & 0 \\
\hline
\end{tabular}

Table 4

NLS solution summary for the gas consumption model (upper half of table) and the parameters of the $N D D_{\mathrm{CA}}$ (lower half).

\begin{tabular}{lllll}
\hline Parameter & Estimate & Standard Error & t-Value & $p$-Value \\
\hline$b_{0}$ & 5.983 & 0.677 & 8.838 & $7.19 \mathrm{E}-18^{* * *}$ \\
$\Delta b_{0, \text { Oct'10-Sept'11 }}$ & -0.955 & 0.4089 & -2.335 & $0.0198^{*}$ \\
$\Delta b_{0, \text { Oct'09-Sept'10 }}$ & -0.9329 & 0.3945 & -2.365 & $0.0183^{*}$ \\
$b_{1}$ & 4.749 & 0.1303 & 36.44 & $1.65 \mathrm{E}-166^{* * *}$ \\
$\Delta b_{1, \text { Oct'10-Sept'11 }}$ & 0.3329 & 0.06131 & 5.429 & $7.70 \mathrm{E}-08^{* * *}$ \\
$\Delta b_{1, \text { Oct'09-Sept'10 }}$ & 0.2423 & 0.05968 & 4.059 & $5.45 \mathrm{E}-05^{* * *}$ \\
\hline$T_{\mathrm{B}, \text { upr }}$ & 22.11 & 0.4506 & - & $-{ }^{\mathrm{a}}$ \\
$T_{\mathrm{B}, \text { lwr }}$ & 7.046 & 0.5559 & - & $-{ }^{\mathrm{a}}$ \\
$\gamma_{1}$ & 0.001774 & $6.61 \mathrm{E}-05$ & 26.85 & $4.64 \mathrm{E}-111^{* * *}$ \\
$\gamma_{2}$ & 0.01799 & 0.001444 & 12.46 & $1.86 \mathrm{E}-32^{* * *}$ \\
$\alpha_{1}$ & 0.4967 & 0.01287 & 38.6 & $1.41 \mathrm{E}-178^{* * *}$ \\
$\omega_{1}$ & 0.3408 & 0.01279 & 26.65 & $7.32 \mathrm{E}-110^{* * *}$ \\
\hline
\end{tabular}

Significance Levels: '*’ $p<0.05$, '**’ $p<0.01$, '***' $p<0.001$

a Standard significance tests are inappropriate for the base temperature parameters.
$N D D_{\text {CA }}$ are shown in Table 4 . We find that the intercept $\left(b_{0}\right)$ and slope $\left(b_{1}\right)$ parameters of the linear model for the most recent gas year are highly significant $(p<0.001)$, while the difference in intercepts $\left(\Delta b_{0} s\right)$ and slopes $\left(\Delta b_{1} s\right)$ for previous gas years relative to the most recent gas year are significant for the intercepts $(p<0.02)$ and highly significant for the slopes. Each of the parameters of the $N D D_{\text {CA }}$ has insignificant standard errors.

The in-sample modelling accuracy of this weekday gas consumption model is shown in the upper plot of Fig. 1. This plot shows the weekday gas consumption values for the three years examined (2009-2012), together with the fitted linear models for each of the three years. We see that $N D D_{\mathrm{CA}}$ estimates consumption for each gas year in a multiple linear regression model with a strong coefficient of determination $\left(R^{2}\right)$ of 0.9859 and a mean absolute percentage error (MAPE) of $7.81 \%$; a MAPE value of $3.53 \%$ is obtained for the upper $5 \%$ of consumption values, above $70.6 \mathrm{GW} \mathrm{h}$, many of which were observed during the extremely cold winter periods in January 
Table 5

NLS solution and in-sample accuracy summaries of incrementally adjusted $H D D$ based variables; and a simplified-NDD $D_{C A}$ variable which omits solar radiation.

\begin{tabular}{|c|c|c|c|c|c|c|c|c|c|c|}
\hline & $H D D^{\mathrm{a}}$ & $\begin{array}{l}H D D_{\mathrm{WA}}^{\mathrm{b}} \\
\left(\gamma_{1} \& \alpha_{1}=0\right)\end{array}$ & $\begin{array}{l}H D D_{\mathrm{WA}}{ }^{\mathrm{c}} \\
\left(\gamma_{2} \& \alpha_{1}=0\right)\end{array}$ & $\begin{array}{l}H D D_{\mathrm{WA}}{ }^{\mathrm{d}} \\
\left(\gamma_{1} \& \gamma_{2}=0\right)\end{array}$ & $\begin{array}{l}H D D_{\mathrm{WA}} \mathrm{e}^{\mathrm{a}} \\
\left(\gamma_{1}=0\right)\end{array}$ & $\begin{array}{l}H D D_{\mathrm{WA}}{ }^{\mathrm{f}} \\
\left(\gamma_{2}=0\right)\end{array}$ & $H D D_{\mathrm{WA}}$ & $N D D_{\mathrm{WA}}$ & $N D D_{\mathrm{CA}}$ & $\begin{array}{l}\text { simplified-NDD } D_{\mathrm{CA}} \mathrm{g} \\
\left(\gamma_{1}=0\right)\end{array}$ \\
\hline \multicolumn{11}{|c|}{ NLS Solution Summary: } \\
\hline$T_{\mathrm{B}}$ & 14.01 & 14.54 & 17.91 & 13.57 & 13.66 & 16.33 & 16.07 & - & - & - \\
\hline$T_{\mathrm{B}, \mathrm{upr}}$ & - & - & - & - & - & - & - & 20.24 & 22.11 & 18.97 \\
\hline$T_{\mathrm{B}, \mathrm{lwr}}$ & - & - & - & - & - & - & - & 12.26 & 7.046 & 1.589 \\
\hline$\gamma_{1}$ & - & - & 0.003562 & - & - & 0.002319 & 0.002095 & 0.002127 & 0.001774 & - \\
\hline$\gamma_{2}$ & - & 0.03976 & - & - & 0.02484 & - & 0.01276 & 0.01251 & 0.01799 & 0.04436 \\
\hline$\alpha_{1}$ & - & - & - & 0.7041 & 0.6575 & 0.6547 & 0.6127 & 0.6154 & 0.4967 & 0.4447 \\
\hline$\omega_{1}$ & - & - & - & - & - & - & - & - & 0.3408 & 0.489 \\
\hline \multicolumn{11}{|c|}{ In-sample Model Accuracy: } \\
\hline $\begin{array}{l}R^{2} \\
\text { MAPE }^{\mathrm{h}}:\end{array}$ & 0.8452 & 0.8749 & 0.9372 & 0.9214 & 0.9359 & 0.9692 & 0.9734 & 0.9755 & 0.9859 & 0.9677 \\
\hline Overall & 26.75 & 24.19 & 16.93 & 17.87 & 16.43 & 11.82 & 11.28 & 10.16 & 7.805 & 11.449 \\
\hline Peak & 7.433 & 6.723 & 4.966 & 5.246 & 6.013 & 3.679 & 4.137 & 4.219 & 3.533 & 5.027 \\
\hline
\end{tabular}

Independent Variable Notes:

(a) Outdoor temperature only (see Eq. (A.1)).

(b) Wind-speed and outdoor temperature only (see Eq. (A.2)).

(c) Solar radiation and outdoor temperature only (see Eq. (A.2)).

(d) Effective outdoor temperature (thermal memory) only (see Eq. (A.2)).

(e) Wind-speed and effective outdoor temperature only (see Eq. (A.2)).

(f) Solar radiation and effective outdoor temperature only (see Eq. (A.2)).

(g) Simplified- $N D D_{\text {CA }}$ variable which omits solar radiation (see Eq. (A.3)).

Model Accuracy Note:

(h) MAPEs are reported for the linear model: overall and for the upper 5\% of consumption values above $70.6 \mathrm{GW}$ h (see Fig. 1).

and December 2010.

The in-sample modelling accuracy using HDDs is shown in the lower plot of Fig. 1. The improvement in modelling accuracy obtained by using $N D D_{\mathrm{CA}}$ is evident; $R^{2}$ increases from 0.8452 to 0.9859 while the MAPE decreases from $26.7 \%$ to $7.81 \%$. This is because $H D D$ only accounts for the effect of outdoor temperature, whereas $N D D_{\text {CA }}$ accounts for each of the effects described in Table 2. We also see that the MAPE result for upper consumption values is less than half of that reported for the HDD model, thus illustrating the relative inaccuracy of a simple temperature variable compared to $N D D_{\mathrm{CA}}$ in estimating peak gas consumption.

In order to assess the improvement of this modelling approach, compared to existing approaches, the accuracies of the incrementally improved estimators of gas consumption summarised in Section 3.2 (and detailed in Appendix A) were assessed. Table 5 reports the results for different models incorporating:

- standard HDD in Eq. (A.1);

- weather adjusted $H D D_{\mathrm{WA}}$ in Eq. (A.2) with various combinations of its parameters set to zero to assess the contribution of each to the accuracy of the model;

- weather adjusted $N D D_{\mathrm{WA}}$ in Eq. (A.3b);

- $N D D_{\mathrm{CA}}$ in Eq. (A.3); and

- a simplified- $N D D_{C A}$ that omits solar radiation in order to assess the overall benefit of accounting for solar heat gains.

As seen in Table 5, the in-sample model accuracy of the gas consumption model improves with each of the incremental adjustments to $H D D$, and that $N D D_{\mathrm{CA}}$ is the most accurate estimator overall. This is shown by the models' $R^{2}$ and MAPE values, in relation to overall accuracy and for peak consumption values. The solar radiation $\left(\gamma_{1}\right)$ and the effective outdoor temperature $\left(\alpha_{1}\right)$ parameters both account for the largest increase in model accuracy from that observed for HDD; $R^{2}$ increases from 0.8452 to 0.9372 and 0.9214 respectively when these parameters are included separately, to 0.9692 when they are included together.

A comparison of the results for $N D D_{\mathrm{CA}} \mathrm{S}$ and simplified- $N D D_{\mathrm{CA}} \mathrm{S}$ reveals that solar radiation accounts for an improvement in accuracy of $3.64 \%$ overall (MAPE reduces from $11.45 \%$ to $7.81 \%$ ), and $1.49 \%$ for peak consumption values. Separate validation tests of these variables using out-of-sample gas consumption and temperature, wind-speed, and solar radiation data with day-ahead forecast errors (see Section 3.2), found that solar radiation accounts for a statistically significant $2.83 \%$ improvement in overall modelling accuracy (on weekdays between October 2012; March 2013). These improvements to in-sample modelling and out-ofsample forecasting accuracy demonstrate the benefit of accounting for the solar radiation effect in both peak-day and daily gas consumption forecasting.

\subsection{Peak consumption estimates}

In this study, peak daily gas consumption is estimated from two alternative supply standard perspectives, based on: 1 ) a peak-day supply standard that applies a 1 -in-50 year $N D D_{\mathrm{CA}}$ return level, similar to the Irish and Dutch supply standards; and 2) a peak-week supply standard that applies a 1-in-20 year 7-day average $N D D_{\text {CA }}$ return level, similar to the EU's supply standard. These estimates are used to illustrate the relative difference in peak daily consumption levels required by such alternative standards.

\subsubsection{Peak-day supply standard}

In this section, peak daily gas consumption is estimated for the Irish domestic and SME gas market for the year ahead, based on a 1in-50 year $N D D_{\mathrm{CA}}$ (or $N D D_{\mathrm{CA}, 0.02}$ ) return level extrapolated from a GEV model.

Table 6 presents the results for the GEV model fitted to gas-year or block maxima $N D D_{\mathrm{CA}}$ values that have been sampled from a $N D D_{\text {CA }}$ series calculated using the $N D D_{\text {CA }}$ parameter estimates of Table 4 and climate data since 1976 (see Section 3.1.2). The result of the Anderson-Darling goodness-of-fit test presented in Table 6 compares the GEV distribution to the empirical data. We find a positive result, which confirms the suitability of this GEV distribution as an appropriate model of the observed block maxima $N D D_{\mathrm{CA}}$ series. This GEV model fit can be assessed visually by the return level plot shown in Fig. 2. 
Table 6

Solution summary for the GEV model of block maxima $N D D_{\mathrm{CA}}$ values.

\begin{tabular}{|c|c|c|c|}
\hline \multirow[t]{2}{*}{ Parameters: } & $\mu$ & $\sigma$ & $k$ \\
\hline & 13.74 & 1.333 & -0.05375 \\
\hline \multirow[t]{2}{*}{ Goodness of Fit: } & $A^{2}(n=36)$ & & \\
\hline & 0.3548 & & \\
\hline \multirow[t]{2}{*}{$\overline{\text { Critical values (Ahmad, 1989): }}$} & $A^{2}(n=35)$ & & \\
\hline & 0.572 & & \\
\hline Null Hypothesis $\left(H_{0}\right)$ & Accepted & & \\
\hline
\end{tabular}

Goodness-of-fit notes:

$A^{2}$ : is the Anderson-Darling test statistic for $n$ block-maxima values.

$H_{0}$ : the empirical data follow the fitted GEV distribution.

Significance level: 0.05 .

Critical region: $H_{0}$ is rejected if goodness of fit result is greater than the critical values reported.

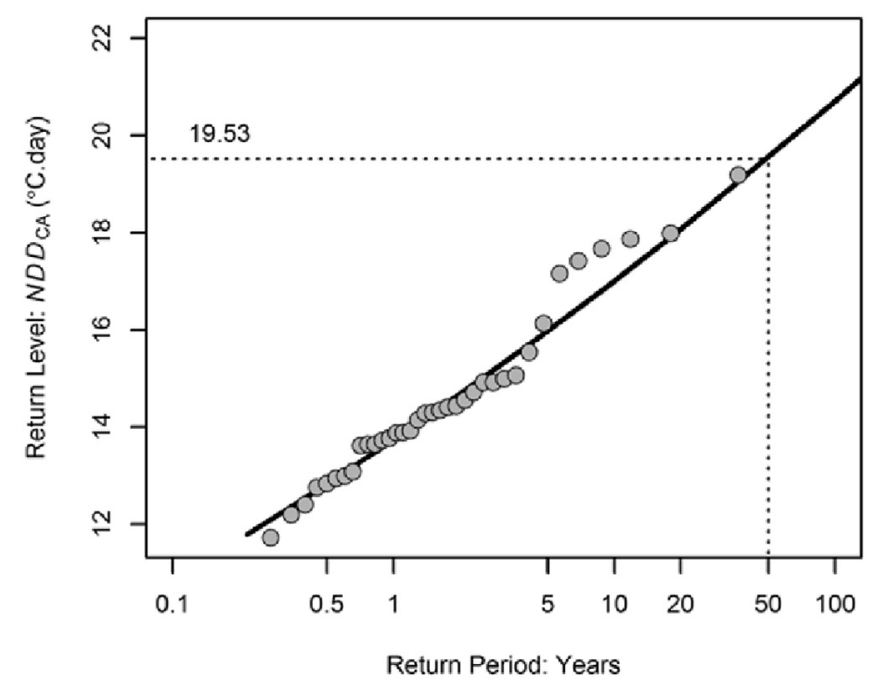

Fig. 2. Empirical (points) and the GEV model's (black line) $N D D_{\mathrm{CA}}$ return level estimates.

Fig. 2 also reports a 1 -in-50 year $N D D_{\mathrm{CA}}$ return level of $19.53{ }^{\circ} \mathrm{C} \cdot$ day, which was calculated using an inverse distribution function for the estimated GEV model (Hosking et al., 1985). Based on this return level, the 1 -in-50 year peak-day gas consumption for the next gas year (2012-'13) is estimated as $98.72 \mathrm{GW} \mathrm{h}$, using the gas consumption forecast model of Eq. (2) and the $b_{0}$ and $b_{1}$ parameters reported in Table 4.

Although the gas consumption model was estimated using weekday gas consumption, this distinction was not applied to the long-term $N D D_{\mathrm{CA}}$ series as part of the GEV modelling process. An adjustment is required to account for the probability of an extreme $N D D_{\text {CA }}$ value occurring at a weekend or on a holiday when gas consumption is lower than on weekdays. The proportion of normalweekdays to the number of days in the long-term climate data series is used to scale down the 1-in-50 year return period to an effective return period which can be used to calculate a 1-in-50

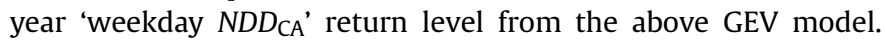
Based on this method, the effective return period is approximately 34 years, with a 1 -in-50 year 'weekday $N D D_{\mathrm{CA}}$ ' return level of $18.89{ }^{\circ} \mathrm{C}$.day. From this, the 1 -in-50 year peak weekday consumption is reduced from $98.72 \mathrm{GW}$ h to $95.7 \mathrm{GW}$ h.

\subsubsection{Peak-week supply standard}

In this section, a peak-week supply standard is applied to the Irish domestic and SME gas market to illustrate: 1) the relative difference in peak daily consumption levels required by such standards compared to a peak-day supply standard; and 2) to identify any change in GEV goodness-of-fit results for the 7-day average $N D D_{\mathrm{CA}}\left(N D D_{\mathrm{CA}, \mathrm{AVG}, 7 \mathrm{D})}\right.$ variable compared to the daily $N D D_{\text {CA }}$ variable.

The second GEV model required for these assessments was fitted to gas-year or block maxima $N D D_{\mathrm{CA}, \mathrm{AVG}, 7 \mathrm{D}}$ values sampled since 1976. The goodness-of-fit result for this model was better than that observed for the first GEV model in Table 6, as the $A^{2}$ (goodness-of-fit) statistic decreased from 0.3548 to 0.119 , further away from the corresponding critical value of 0.572 in Table 6. This improvement in GEV model fit can be visually inspected by comparing the return level plot in Fig. 3 to Fig. 2.

Fig. 3 also reports a 1 -in-20 year $N D D_{\mathrm{CA}, \mathrm{AVG}, 7 \mathrm{D}}$ return level of $16.25^{\circ} \mathrm{C}$. day. Using this return level, peak-day gas consumption for the next gas year is estimated as $83.14 \mathrm{GW} \mathrm{h}$. This estimate is approximately $13 \%$ lower than the $95.7 \mathrm{GW}$ h estimated to the 1 -in50 year peak-day supply standard, in Section 4.2.1.

\section{Conclusion}

The $N D D_{\text {CA }}$ variable developed in this study is shown to be an accurate estimator of domestic and SME gas market consumption, accounting for numerous weather effects and gas consumption dynamics and improving on existing approaches. Parameters for the variable were estimated for the Irish NDM gas market using gas consumption and weather data over a three-year period. The model's coefficient of determination was almost 0.99 , compared to 0.85 and 0.97 for existing approaches.

To estimate these parameters, we developed a non-linear least squares model that included differential intercepts and slopes to account for gas market conditions of previous gas years. Using this methodology, each parameter of the $N D D_{\mathrm{CA}}$ estimator was also quantified and found to be significant. A comparative analysis of modelling approaches using HDDs and incrementally adjusted HDD

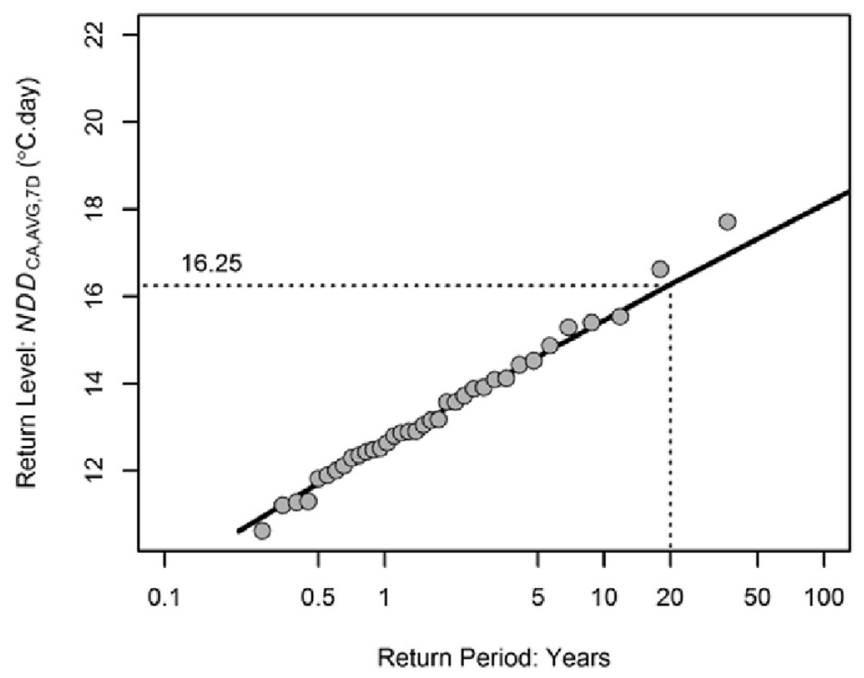

Fig. 3. Empirical (points) and the second GEV model's (black line) $N D D_{\mathrm{CA}, \mathrm{AVG}, 7 \mathrm{D}}$ return level estimates. 
variables similar to those used by TSOs found that accounting for the effects of solar radiation and the thermal memory of buildings contributed the most significant improvements to model accuracy.

Although the addition of solar radiation greatly reduced the number of years of climate data available to develop an extreme value model, goodness-of-fit tests indicate that GEV models are an appropriate representation of the block maxima $N D D_{C A}$ series. We also found that the year-ahead estimate of peak-day gas consumption based on a 1-in-20 year peak-week supply standard is approximately $13 \%$ lower than that based on a 1 -in-50 year peakday supply standard.

The methodology presented in this study can be used by natural gas TSOs to inform network planning decisions both to safeguard against diminished supply capacity during extreme cold weather conditions and to avoid over-investment, thus helping to ensure economically efficient and secure gas networks.

\section{Acknowledgements}

This study was supported by Dublin Institute of Technology and Gas Networks Ireland under Dublin Institute of Technology's Fiosraigh Enterprise Scheme. The authors also wish to acknowledge Met Eireann for providing the metrological data used to develop $N D D_{\text {CA. }}$

\section{Appendix A. Derivation of climate-adjusted network degree days}

$N D D_{\text {CA }}$ is developed in this appendix based on a series of adjustments to the standard HDD approach commonly used to model building heating system fuel consumption. It is based on HDDs because gas consumed by the domestic and SME gas market in Northern Europe is primarily used for the purpose of heating buildings. The gas consumption model in Eq. (1) shows, for example, that $81 \%$ of the weekday gas consumption in the gas year 2011-2012 in Ireland was weather-dependent, and can be reasonably assumed to have been for heating purposes.

HDDs are an established estimator of building heating system fuel consumption that are based on outdoor temperature data. However, as HDDs are normally applied in models of monthly to quarterly gas bill meter readings, they do not account for the effect of solar radiation, wind-speed and thermal memory. Such effects may be estimated by weather adjusted HDDs ( $\left.H D D_{\mathrm{WA}} \mathrm{s}\right)$. This CWV can be used to estimate the daily fuel consumption of smart metered buildings, for example. $N D D_{\mathrm{CA}}$ is based on $H D D_{\mathrm{WA}}$ and is used to account for the additional network level effects of seasonal consumption and variable building base temperatures across the consumer population.

$H D D\left({ }^{\circ} \mathrm{C}\right.$-day) is an estimate of the indoor-outdoor temperature differential between a building's heated space and surrounding environment which necessitates heat consumption each day, and is given by:

$H D D=\max \left(0 ; T_{\mathrm{B}}-T_{\mathrm{O}, \mathrm{AVG}, \mathrm{D}}\right)$

where: $T_{\mathrm{B}}\left({ }^{\circ} \mathrm{C}\right)$ is the building's base temperature parameter, which traditionally has an assumed value of $15.5{ }^{\circ} \mathrm{C}$ (Day, 2006), but is estimated here as part of the regression procedure (see Section 3.3 and Table 5). It is used to estimate the average internal temperature of the building over the heating season, less the equivalent temperature effect of heat gains. $T_{\mathrm{O}, \mathrm{AVG}, \mathrm{D}}\left({ }^{\circ} \mathrm{C}\right)$ is the average outdoor temperature for the day (D).

$H D D_{\mathrm{WA}} \mathrm{s}$ are used to estimate gas consumption dynamics that are not readily modelled using gas bill meter reading data, and hence are not estimated by $H D D s . H D D_{\mathrm{WA}}\left({ }^{\circ} \mathrm{C} \cdot\right.$ day $)$ accounts for the additional effects of solar radiation, building fabric thermal 'memory' and wind speed, and is given by:

$$
H D D_{\mathrm{WA}, \mathrm{D}}=H D D_{\mathrm{S} \& T M, D}+E-H D D_{\mathrm{WS}, \mathrm{D}}
$$

where: $H D D_{\mathrm{S} \& \mathrm{TM}, \mathrm{D}}\left({ }^{\circ} \mathrm{C} \cdot\right.$ day $)$ is given by Eqs. (A.2b)-(A.2e), and is the $H D D$ in Eq. (A.1) adjusted for the effects of solar gain and thermal memory for the given day (D); and $E-H D D_{\mathrm{WS}, \mathrm{D}}\left({ }^{\circ} \mathrm{C} \cdot\right.$ day) is given by Eq. (A.2f), and is used to account for the equivalent heating degree day effect due to wind speed - as this heat loss is a multiple of the wind induced air-infiltration rate and the degree day temperature differential, its effect is estimated as an adjustment in degree days so that it can be included within the CWV to allow simple linear and extreme value modelling.

The $H D D_{\mathrm{S} \& \mathrm{TM}}$ required to estimate $H D D_{\mathrm{WA}}$ is given by:

$H D D_{\mathrm{S} \& T M, D}=\max \left(0 ; T_{\mathrm{B}}-T_{\mathrm{S} \& T M, D}\right)$

$T_{\mathrm{S} \& T M, D}=T_{\mathrm{SG}, \mathrm{D}}+T_{\mathrm{EFF}-\mathrm{O}, \mathrm{D}}$

where: $T_{\mathrm{S} \& \mathrm{TM}, \mathrm{D}}\left({ }^{\circ} \mathrm{C}\right)$ is a temperature used to account for the combined effect of solar gain and thermal memory; $T_{\mathrm{SG}, \mathrm{D}}\left({ }^{\circ} \mathrm{C}\right)$ is given by Eq. (A.2d), and is the equivalent temperature effect of solar gains, which is seen to decrease the degree day temperature differential as required; and $T_{\mathrm{EFF}-\mathrm{O}, \mathrm{D}}\left({ }^{\circ} \mathrm{C}\right)$ is given by Eq. (A.2e), which is similar to the effective (outdoor) temperature used in the UK's CWV (National Grid, 2012), and is used to account for the effect of building fabric thermal memory by delaying the effect of outdoor temperature over time.

Each of the required $H D D_{\mathrm{WA}}$ adjustments is estimated as follows:

$T_{\mathrm{SG}, \mathrm{D}}=\gamma_{1} G R_{\mathrm{D}}$

$T_{\mathrm{EFF}-\mathrm{O}, \mathrm{D}}=\left(1-\alpha_{1}\right) T_{\mathrm{O}, \mathrm{AVG}, \mathrm{D}}+\alpha_{1} T_{\mathrm{EFF}-\mathrm{O}, \mathrm{D}-1} ; 0 \leq \alpha_{1} \leq 1$

$E-H D D_{\mathrm{WS}, \mathrm{D}}=\gamma_{2} W S_{\mathrm{AVG}, \mathrm{D}} H D D_{\mathrm{S} \& T M, D}$

where: $T_{\mathrm{SG}, \mathrm{D}}$ is estimated using $G R_{\mathrm{D}}\left(\mathrm{J} / \mathrm{cm}^{2}\right)$, the total global radiation energy per unit area and the coefficient $\gamma_{1} ; T_{\mathrm{EFF}-\mathrm{O}, \mathrm{D}}$ is estimated using recent $T_{\mathrm{O}, \mathrm{AVG}}\left({ }^{\circ} \mathrm{C}\right)$ average outdoor temperature values with an exponential filter using the $\alpha_{1}$ parameter; $E-H D D_{\mathrm{WS}, \mathrm{D}}$ is estimated as the product of $W S_{A V G, D}$ (knots) the average wind speed value, the coefficient $\gamma_{2}$ and $H D D_{\mathrm{S} \& \mathrm{TM}}$; and where $T_{\mathrm{B}}$ (Eq. (A.2b)), $\gamma_{1}$, $\gamma_{2}$ and $\alpha_{1}$ can be solved iteratively using non-linear least square methods (see Section 3.3).

$N D D_{\text {CAS }}$ are used to estimate gas consumption effects that are not readily modelled at the level of an individual building, and hence are not estimated by the $H D D_{\mathrm{WA}} \mathrm{S} . N D D_{\mathrm{CA}}\left({ }^{\circ} \mathrm{C} \cdot\right.$ day $)$ accounts for the additional network level effects of variable building base temperatures and seasonal consumption, and is given by:

$N D D_{\mathrm{CA}, \mathrm{D}}=\left(1-\omega_{1}\right) N D D_{\mathrm{WA}, \mathrm{D}}+\omega_{1} S S-N D D_{\mathrm{WA}, \mathrm{D}}$

where: $N D D_{\mathrm{WA}, \mathrm{D}}$ is given by Eqs. (A.3b)-(A.3d) and Eq. (A.2c), and is the weather adjusted network degree day for the given day (D) that is based on the $H D D_{\mathrm{WA}}$ in Eq. (A.2) and the alternative transformation function in Eq. (A.3c); and $S S-N D D_{\mathrm{WA}}$ is given by Eqs. (A.3e) and (A.3f), and is the corresponding smoothed seasonal value of the $N D D_{\mathrm{WA}}$, which is used with the coefficient $\omega_{1}$ to account for the effect of seasonal consumption.

$N D D_{\mathrm{WA}}$ is required as part of $N D D_{\mathrm{CA}}$ and is given by: 


$$
N D D_{\mathrm{WA}, \mathrm{D}}=N D D_{\mathrm{S} \& T M, D}+E-N D D_{\mathrm{WS}, \mathrm{D}}
$$

SME small-to-medium enterprise

$S-N D D$ seasonal $N D D\left({ }^{\circ} \mathrm{C} \cdot\right.$ day $)$

$S S-N D D$ smoothed seasonal $N D D\left({ }^{\circ} \mathrm{C} \cdot\right.$ day $)$

$N D D_{\mathrm{S} \& T M, D}=\left\{\begin{array}{l}0 ; \text { if } T_{\mathrm{S} \& T M, D}>T_{\mathrm{B}, \text { upr }} \\ \left(T_{\mathrm{S} \& M, D}-T_{\mathrm{B}, \text { upr }}\right)^{2} / 2\left(T_{\mathrm{B}, \text { upr }}-T_{\mathrm{B}, \mathrm{lwr}}\right) ; \text { for } T_{\mathrm{B}, \mathrm{lwr}}<T_{\mathrm{S} \& T M, D} \leq T_{\mathrm{B}, \text { upr }} \\ \left(T_{\mathrm{B}, \mathrm{upr}}+T_{\mathrm{B}, \mathrm{lwr}}\right) / 2-T_{\mathrm{S} \& T M, D} ; \text { if } T_{\mathrm{S} \& T M, D} \leq T_{\mathrm{B}, \mathrm{lwr}}\end{array}\right.$

$E-N D D_{\mathrm{WS}, \mathrm{D}}=\gamma_{2} W S_{\mathrm{AVG}, \mathrm{D}} N D D_{\mathrm{S} \& T M, D}$

where: $N D D_{\text {S\&TM }}$ is $H D D_{\text {S\&TM,D }}$ in Eq. (A.2b) adjusted for the effect of varying building base temperatures using the transformation function in Eq. (A.3c) (Papalexopoulos and Hesterberg, 1990), which models an observed curve in the temperature-gas consumption relationship between upper $T_{\mathrm{B} \text {,upr }}$ and lower $T_{\mathrm{B}, \mathrm{lwr}}$ base temperature parameters, due to decreasing consumption rates in mild weather periods at the onset of summer and vice-versa at the onset of winter; $E-N D D_{\text {WS }}$ is the equivalent degree day effect of wind speed; and where $\omega_{1}$ (Eq. (A.3a)), $T_{\mathrm{B}, \mathrm{upr}}, T_{\mathrm{B}, \mathrm{lwr}}$ (Eq. (A.3c)), $\gamma_{1}$ (Eq. (A.2d)), $\gamma_{2}$ (Eq. (A.3d)) and $\alpha_{1}$ (Eq. (A.2e)) can be solved iteratively using non-linear least square methods (see Section 3.3).

$S S-N D D_{\mathrm{WA}}$ is required as part of $N D D_{\mathrm{CA}}$ and is given by:

$$
\begin{aligned}
& S S-N D D_{\mathrm{WA}, \mathrm{D}} \\
& =\left\{\begin{array}{l}
\frac{1}{m} \sum_{i=-j}^{j} S-N D D_{\mathrm{WA}, d+i} ; \text { for } D \neq \mathrm{Feb}^{\prime} 29 \text { th } \\
0.5\left(S S-N D D_{\mathrm{WA}, \mathrm{D}-1}+S S-N D D_{\mathrm{WA}, \mathrm{D}+1}\right) ; \text { for } D=\text { Feb }^{\prime} 29 \text { th }
\end{array}\right.
\end{aligned}
$$

$S-N D D_{\mathrm{WA}, \mathrm{D}}=\frac{1}{n} \sum_{i=0}^{n-1} N D D_{\mathrm{WA}, d+365 i} ;$ Feb' 29 th $\notin$ climate data

where: $d$ is the corresponding day of year number for a non-leap year; $m$ is the order of the moving average filter, $j=(m-1) / 2$; $S$ $N D D_{\text {WA,D }}\left({ }^{\circ} \mathrm{C}\right.$-day) is the seasonal value of $N D D_{\mathrm{WA}}$; and $n$ is the number of years of climate data used to calculate each seasonal value; and where $m$ and $n$ are manually specified parameters (see Section 3.3).

\section{Appendix B. Abbreviations}

$\begin{array}{ll}\mathrm{A}^{2} & \text { Anderson-Darling test statistic } \\ \mathrm{AD} & \text { Anderson-Darling } \\ \mathrm{C} & \text { gas consumption }(\mathrm{GWh}) \\ \mathrm{CWV} & \text { composite weather variable } \\ E-H D D & \text { equivalent } \mathrm{HDD}\left({ }^{\circ} \mathrm{C} \cdot \text { day }\right) \\ E-N D D & \text { equivalent } \mathrm{NDD}\left({ }^{\circ} \mathrm{C} \cdot \text { day }\right) \\ G R & \text { global radiation }\left(\mathrm{J} / \mathrm{cm}^{2}\right) \\ H D D & \text { heating degree day }\left({ }^{\circ} \mathrm{C} \cdot \text { day }\right) \\ \text { MAPE } & \text { mean absolute percentage error } \\ \text { NDD } & \text { network degree day }\left({ }^{\circ} \mathrm{C} \cdot \text { day }\right) \\ \text { NDM } & \text { non-daily metered } \\ \text { NLS } & \text { non-linear least squares } \\ \text { NWP } & \text { numerical weather prediction }\end{array}$

$\begin{array}{ll}T & \text { temperature }\left({ }^{\circ} \mathrm{C}\right) \\ \text { TSO } & \text { transmission system operator } \\ \text { WS } & \text { wind speed (knots) }\end{array}$

Subscripts

7D seven days

AVG average

B base

CA climate-adjusted

D date/day

d day of year

EFF effective

lwr lower

O outdoor

P period (years)

S\&TM solar and thermal memory

SG solar gain

upr upper

WA weather-adjusted

WS wind speed

WD weekday

\section{Superscripts}

estimate/forecast

Greek symbols

$\begin{array}{ll}\alpha, \gamma, \omega & N D D_{\mathrm{CA}} \text { internal parameters } \\ \varepsilon & \text { model error } \\ \mu, \sigma, k & \text { GEV model parameters }\end{array}$

\section{References}

ACIL Tasman, 2012. Review of Demand Forecasts for Multinet, 2012. http://www. aer.gov.au/system/files/ACIL\%20Tasman\%20-\%20Demand\%20forecast\%20review \%20\%20Multinet\%20VF\%20August\%202012.pdf (Accessed 21 September 2015).

Ahmad, M.I., 1989. Applications of Statistics in Flood Frequency Analysis. University of St Andrews.

Aras, H., Aras, N., 2004. Forecasting residential natural gas demand. Energy Sources 26, 463-472. http://dx.doi.org/10.1080/00908310490429740.

Brabec, M., Konár, O., Pelikán, E., Malý, M., 2008. A nonlinear mixed effects model for the prediction of natural gas consumption by individual customers. Int. J. Forecast. 24, 659-678. http://dx.doi.org/10.1016/j.ijforecast.2008.08.005.

Brabec, M., Maly, M., Pelikan, E., Konar, O., 2010. Statistical model of segmentspecific relationship between natural gas consumption and temperature in daily and hourly resolution. Nat. Gas. http://dx.doi.org/10.5772/9855.

Brown, R.H., Kharouf, P., Feng, X., Piessens, L.P., Nestor, D., 1994. Development of feed-forward network models to predict gas consumption. In: Neural Networks, 1994. IEEE World Congress on Computational Intelligence. 1994 IEEE International Conference on, vol. 2, pp. 802-805. http://dx.doi.org/10.1109/ ICNN.1994.374281.

Czech Energy Regulatory Office, 2011. The Czech Republic's National Report on the Electricity and Gas Industries for 2010. Available: http:/www.ceereu/portal/ page/portal/EER_HOME/EER_PUBLICATIONS/NATIONAL_REPORTS/National\% 20Reporting\%202011/NR_En/C11_NR_Czech\%20Rep-EN.pdf (Accessed 21 September 2015).

Day, T., 2006. Degree Days: Theory and Application. The Chartered Institution of Building Services Engineers, London.

Energinet, 2011. Gas in Denmark: Security of Supply and Development. Available: 
http://www.energinet.dk/SiteCollectionDocuments/Engelske\%20dokumenter/ Gas/Gas\%20in\%20Denmark\%202011.pdf (Accessed 21 September 2015).

European Commission, 2011. Implementation of Regulation 994/2010 on Security of Gas Supply in the EU. Available: http://www.energy-community.org/pls/portal/ docs/1122184.PDF (Accessed 21 September 2015).

FPS Economy, 2014. Risk Assessment Belgium, 2014. Available: http://economie. fgov.be/nl/binaries/Risk_Assessment_tcm325-179867.pdf (Accessed 21 September 2015).

Gas Networks Ireland, 2007. Distribution LDM, DM and NDM Supply Point Capacity Setting Procedure - Draft for Approval. Available: http://www.gasnetworks.ie Global/Gas\%20Industry/BGN\%20Gas\%20Industry\%20Website\%20Content/Gas\% 20Industry\%20Documents/GNI\%20Files/Code\%20of\%200perations\% 20Documents/GL024_DistributionLDMDMSP.pdf (Accessed 21 September 2015).

Gas Transport Services BV, 2011. Risk Assessment - The Netherlands. Available: http://www.government.nl/files/documents-and-publications/reports/2011/12 02/risk-assessment-natural-gas-2011/risk-assessment-natural-gas-2011.pdf (Accessed 21 September 2015).

GRTgaz, 2009. Évolution de la demande de gaz naturel sur le réseau de transport de GRTgaz - Hypothèses GRTgaz 2009-2018. Available: http://www.grtgaz.com/ fileadmin/grands_projets/eridan/documents/fr/quoi_de_neuf/projets_evol_ demande.pdf (Accessed 21 September 2015).

GRTgaz, 2013. Ten Year Development Plan for the GRTgaz Network - 2013-2022 Period. Available: http://www.grtgaz.com/fileadmin/plaquettes/en/ 10years2013_2022_EN.pdf (Accessed 21 September 2015).

Hosking, J.R.M., Wallis, J.R., Wood, E.F., 1985. Estimation of the generalized extremevalue distribution by the method of probability-weighted moments. Technometrics 27, 251-261. http://dx.doi.org/10.2307/1269706.

Insight_E, 2014. Strengths and Weaknesses of the European Union Gas Security of Supply, 2014. Available: http://www.insightenergy.org/static_pages/ publications\#?publication=2 (Accessed 21 September 2015).

Khotanzad, A., Elragal, H., Lu, T.L., 2000. Combination of artificial neural-network forecasters for prediction of natural gas consumption. Neural Netw. IEEE Trans. 11, 464-473. http://dx.doi.org/10.1109/72.839015.

Kizilaslan, R. and Karlik, B. (2008), Comparison neural networks models for short term forecasting of natural gas consumption in Istanbul, in Applications of Digital Information and Web Technologies, 2008. ICADIWT 2008. First International Conference on the, 2008, pp. 448-453, DOI: 10.1109/ ICADIWT.2008.4664390.

Lorenz, E., Remund, J., Müller, S.C., Traunmüller, W., Steinmaurer, G., Pozo, D., et al. 2009. Benchmarking of different approaches to forecast solar irradiance. In: 24th European Photovoltaic Solar Energy Conference, Hamburg, Germany, vol. 21. http://dx.doi.org/10.4229/24thEUPVSEC2009-5BV.2.50.

MET Eireann, 2014. Met Eireann Researchers in European Collaboration to Improve Forecasts for the Solar Energy Industry, 2014. Available: http://www.met.ie/ news/display.asp?ID=277 (Accessed 21 September 2015).

Met Office, 2015. How Accurate Are Our Public Forecasts? http://www.metoffice. gov.uk/about-us/who/accuracy/forecasts (Accessed 21 September 2015).

National Grid, 2012. Gas Demand Forecasting Methodology. Available: http://www. nationalgrid.com/NR/rdonlyres/71CFD0F6-3607-474B-9F37-0952404976FB/ 52071/GasDemandForecastingMethodologyFeb12.pdf (Accessed 21 September 2015)

Nielsen, K.P., Gleeson, E., Rontu, L., 2014. Radiation sensitivity tests of the HARMONIE 37h1 NWP model. Geosci. Model Dev. 7, 1433-1449. http://dx.doi.org/ 10.5194/gmd-7-1433-2014.

Official Journal of the European Union, 2010. Regulation (EU) No 994/2010 of the European Parliament and of the Council of 20 October 2010 Concerning Measures to Safeguard Security of Gas Supply and Repealing Council Directive 2004/ $67 / E C$.

Papalexopoulos, A.D., Hesterberg, T.C., 1990. A regression-based approach to shortterm system load forecasting. Power Syst. IEEE Trans. 5, 1535-1547. http:// dx.doi.org/10.1109/59.99410.

Peharda, D., Delimar, M., Loncaric, S., 2001. Short term hourly forecasting of gas consumption using neural networks, in Information Technology Interfaces, 2001. ITI 2001. In: Proceedings of the 23rd International Conference on, 2001, vol. 1, pp. 367-371.

Soldo, B., Potočnik, P., Šimunović, G., Šarić, T., Govekar, E., 2014. Improving the residential natural gas consumption forecasting models by using solar radiation. Energy Build. 69, 498-506. http://dx.doi.org/10.1016/ j.enbuild.2013.11.032. 